\title{
Modern methods for assessing the cariogenic and erosive potential of foods
}

\author{
M. E. J. Curzon, ${ }^{1}$ and J. J. Hefferren, ${ }^{2}$
}

$\mathrm{D}$ ental caries has often been described as a disease related to the use of diet although, as a multi-factorial disease, oral bacteria, tooth enamel composition and salivary components and consistency are also major factors. The effect of food type, composition, texture, retentiveness, solubility and method of usage have been a focus of much dental research since the early studies of W. D. Miller. Studies on the role of diet and foods involved many different types of research but without any systematic approach. Until the 1970s various models were used from human intervention studies, observational studies and attempts to recreate intra-oral conditions with in vitro systems, artificial mouths, plaque $\mathrm{pH}$, animal models, clearance/retention studies and enamel demineralisation. All these were tried with varying degrees of success.

The formation of the Food, Nutrition and Dental Health Program of the American Dental Health Foundation in 1970 became the basis of a series of research studies, properly controlled and conducted, to assess which methods of evaluation of the cariogenic potential of foods were the most appropriate and reliable. These studies culminated in an international conference in San Antonio (USA) in 1985 published by Hefferren. ${ }^{1}$ The proceedings of this consensus conference were ultimately published in 1986 and have since formed the basis for further research and evaluation of the cariogenic potential of foods. However, since the San Antonio meeting there have been further developments in the methodologies available for cariogenicity as well as development on aspects of food in relation to tooth erosion.

At the San Antonio conference the participating scientists involved agreed on the two main methods available, animal models

Editors: ${ }^{1}$ Professor Child Dental Health, University of Leeds; ${ }^{2}$ Research Professor, University of Kansas

Proceedings of an International Workshop to provide current advice on the methodology to assess the cariogenic and erosive potential of foods

Initiated by the Commonwealth Dental Association in association with the British Dental Association and supported by an educational grant from the Sugar

Bureau, London

Section Editors: Animal Models - M. E. J. Curzon; Plaque pH models - W. M. Edgar; Intra-oral cariogenicity models - D. Zero; Erosion models - A. Milosevi Workshop participants: Commonwealth Dental Association: Dr V. Eastmond, (Univ. Trinidad), Prof. J. Kaimani, (Univ. Nairobi), Dr P. Mtolo, (Univ. Zambia); British Dental Association: Dr J. Hunt, Ms D. Scarrott; Dept. of Health, UK Government: Dr R. Wild; Science and Academia: Dr B. Amaeichi (Univ. Liverpool), Prof. M. E. J. Curzon, (Univ. Leeds), Prof. M. S. Duggal, (Univ.Leeds), Prof. W. M. Edgar, (Univ. Liverpool), Prof. J. J. Hefferen, (Univ. Kansas), Dr S. A. Higham, (Univ. Liverpool), Prof. P. Marsh, (Univ. Leeds), Prof. A. J. Rugg-Gunn, (Univ. Newcastle), Dr A. Milosevic, (Univ. Liverpool), Dr A. Preston (Univ. Leeds), Dr K.J. Toumba, (Univ. Leeds), Prof. D. Zero, (Univ. Indiana); Other contributions by: Prof. M.A. Addy (Univ. Bristol), Prof. W. M. Bowen (Univ. Rochester)

${ }^{\star}$ Correspondence to: Prof. M. E. J. Curzon, Foxgloves, Galphay, North Riding HG4 3NJ

email:curzongalphay@aol.com

REFEREED PAPER

Received 11.10.00; Accepted 09.02.01

(C) British Dental Journal 2001; 191: 41-46 and plaque $\mathrm{pH}$, but also determined that enamel demineralisation should be further developed as a model. Dental erosion was not perceived as a problem, at that time, and was not mentioned in the deliberations. The animal model has continued to be used. Researchers, and other authorities, wishing to determine the cariogenic potential of foods, drinks and some oral medicines, have used the plaque $\mathrm{pH}$ models. The enamel demineralisation model, often called the intra-oral cariogenicity test (ICT), has been further developed since the San Antonio conference, so that it is now widely used for cariogenicity testing. Variants of the ICT, also known as the in situ model, are now being developed to test foods and drinks for erosion, but need evaluation.

Accordingly on 8 and 9 November 1999, a group of dental scientists and clinicians met in London (UK) to review the San Antonio recommendations, reassess them and draw up revised guidelines. The aim was to determine which methods are currently suitable as research tools but also for regulatory assessments.

The conference was directed by Professor John Hefferren, previously Chairman of the San Antonio meeting, and who lead the discussions of all delegates. In each of the four workshop sessions, under the guidance of a chairman, a presenter gave a prepared report to update the information on a particular method or group of methodologies. Each presentation was then commented on by a reactor and then by open discussion of all delegates. On the second day individual workshops were held involving small groups of delegates and working documents prepared presenting draft new guidelines.

In a final plenary session all of the working documents were reconsidered and refined. Subsequently, the chairman of each working group was asked to prepare a draft document that was then circulated and commented upon by all delegates. After final editing the consensus opinions are presented in this document.

\section{Organisation of the text}

The following text is organised to consider the four main groups of models for cariogenicity and erosion evaluation. The first is the animal model, usually based on the rat using an automatic feeding machine. The second group concerns the various approaches to assess plaque $\mathrm{pH}$ responses to the use of foods. The third model is the enamel demineralisation method and the fourth is that concerning assessment of the erosive potential of foods. Readers should consider this document in association with the San Antonio publication ${ }^{1}$ which gives the original guidelines for methodologies in great detail. Herein only suggested changes or comments on the original have been made.

\section{Animal models:}

Workshop group: M. E. J. Curzon, J. J. Hefferren, P. M. Marsh and P. Mtolo

The group agreed that animal testing (usually with the laboratory rat) remains an important model to assess cariostatic and cario- 
genic diets and dietary components for most foods and some drinks. As stated in the San Antonio Working Group report on animal caries, the pathogenesis of caries is essentially the same in rats and humans. The UK group reiterated the guidelines given by the San Antonio conference concerning the use of diets (nutrition and test foods), feeding regimens, use of appropriate controls and statistical evaluation of results. All of these guidelines remain as valid today as in 1985 .

All experiments and tests must be carried out to the highest standards of animal husbandry. All experiments must be undertaken to the requirements of the permitted legislation and regulations pertaining to animal research in any country where it is proposed to undertake this work.

\section{Recommendations}

The recommendations of the San Antonio were extensive and are still valid with respect to diets, feeding regimens, controls, scoring of lesions and statistical considerations. The following further recommendations were made.

\section{Further refinement of the rat model}

Since the San Antonio Conference there have been further refinements to the conduct of studies involving rats. Specifically these require the proper randomisation of pups between test and control groups. ${ }^{2}$ Randomisation of litters is also necessary. ${ }^{3}$ The diagnosis of caries in rat molars should use the technique of Keyes. ${ }^{4,5}$ An alternative method is the use of fluorescent technique, which should now be considered, ${ }^{6}$ although it has not been validated across several laboratories.

Animals should also be screened for the presence of SDV (sialodacryoadenitis virus) that is not always readily apparent clinically but can have a serious effect on the animals' salivary glands.

\section{Research issues}

The UK workshop group expressed concern that the number of laboratories with staff and facilities capable of conducting the animal (rat) model for the assessment of the cariogenicity of foods and diets was becoming limited. This would restrict the breadth of expertise available for the future and is an issue that should be addressed.

\section{Regulatory issues}

There is a move, in many countries, away from the use of animals in research and more particularly in studies for regulatory purposes. This has been coupled with a similar shift in consumer attitudes. Therefore, this emphasises the need for the animal model to be considered as complementary to the plaque $\mathrm{pH}$ and intra-oral cariogenicity test (ICT). The animal model is valuable in areas of dental research where it has unique advantages. These may be exploited for mechanistic studies on dental erosion, saliva effects on caries, erosion and trace element/micronutrient effects on caries. ${ }^{7,8}$

\section{Test and control standards}

The San Antonio workshop on animal models suggested that reference standards be developed to ensure consistency in quality of the negative control. This still remains an issue for further development of the animal model. The UK workshop group recommended that the use of reference food standards was highly desirable for future research using the animal model.

\section{Conclusion}

The UK group on the use of the animal (rat) model emphasised that this model continues to be valid for research and assessment of the cariogenicity of foods, drinks, confectioneries and some oral health products. Where appropriate it should be used in combination with plaque $\mathrm{pH}$ and the intra-oral cariogenicity test (ICT) and can be used to assess foods more reliably and with greater reproducibility than when used singly.

\section{Plaque $\mathrm{pH}$ :}

Workshop group: W. M. Edgar, A. J. Rugg-Gunn, M. S. Duggal, A. Preston

\section{Introduction}

The workshop participants concerned themselves only with developments in plaque $\mathrm{pH}$ issues that have arisen since the San Antonio conference. ${ }^{1}$ It was emphasised that the original San Antonio recommendations for plaque $\mathrm{pH}$ testing still hold true in that each of the three types of methods (plaque sampling, touch electrode, interproximal telemetry) will satisfactorily identify nonacidogenic foods when used properly with appropriate positive (sucrose) and negative (sorbitol) controls.

The topics that were discussed comprised:

- Development of the three established plaque $\mathrm{pH}$ methods (plaque sampling, touch electrode and telemetry) since 1985.

- Published reports of comparisons of the methods since 1985.

- Requirements for any improvements to the methods.

- Recommendations for the use of the methods in the assessment of the cariogenic potential of foodstuffs.

- Use of plaque pH methods in the development of therapeutic agents.

\section{Development of present plaque $\mathrm{pH}$ methods:}

\section{Plaque sampling}

There are three types of electrode commonly used by various research groups for use in plaque sampling $\mathrm{pH}$ studies:

- 'Beetrode' microelectrode with a reference electrode

- 'Microelectrode' combination electrode.

- 'Drop' combination electrode

It was agreed that plaque should be sampled for plaque $\mathrm{pH}$ determination at frequent intervals during the Stephan curve response. This is especially important within the first 10 minutes, as the minimum $\mathrm{pH}$ often occurs during this time. Hence, at least three plaque $\mathrm{pH}$ readings in addition to the baseline reading should be taken within the first 10 minutes. The Stephan curve should be determined for at least 30 minutes.

\section{Touch electrode}

The 'Beetrode' microelectrode (World Precision Instruments, UK) is the favoured electrode by most groups. It is an iridium/iridium oxide electrode which is $0.1 \mathrm{~mm}$ in diameter, thereby making it small enough to fit into interdental embrasures to measure the $\mathrm{pH}$ of interproximal plaque.

Particular points of consideration were:

- Sterilisation - Touch electrodes should be sterilised if they are to be used on different subjects. Studies are required in order to ascertain the most appropriate sterilisation method to use, without compromising the life of the electrode.

- Fragility - 'Beetrode' microelectrodes are fragile and should be handled with care in the in vivo situation.

- Reference electrode - The accepted way in which to establish a reference electrode is to have the subject dip their finger into a vessel containing a $3 \mathrm{M}$ potassium chloride solution and the reference electrode. ${ }^{9}$

\section{Indwelling electrode telemetry}

This method remains popular in a limited number of centres. It has been extensively used in the accreditation of foodstuffs ('tooth- 
friendly'). Further studies should investigate the characterisation of plaque at the inert glass electrode interface and developments that might be possible in improving the miniaturisation of the apparatus. There should be a move towards modifying the apparatus, in such a way that selecting subjects more representative of the general population is possible. At present, only partial denture-wearers are recruited.

\section{Comparison of the three methods}

There have been several recently published reports comparing two or all three of the plaque $\mathrm{pH}$ methods. ${ }^{10-12}$ Generally, it has been shown that the three methods (plaque sampling, touch electrode and telemetry) are comparable and equally valid as methods of testing acidogenic profile.

It is generally accepted that the plaque sampling method is the most practicable method. This is because it is the least cost-intensive method. The telemetry method is the most sophisticated plaque $\mathrm{pH}$ technique and it is said to be the most discriminating between foods.

\section{Improvements to the methodology}

Certain observations were made regarding possible improvements that could be made to current plaque $\mathrm{pH}$ practices. It has been shown that adults generally give a more acidogenic response to a given challenge than children. ${ }^{13,14}$ Therefore, adults are more appropriate as subjects in the plaque $\mathrm{pH}$ testing of foods.

A need for more robust touch microelectrodes was identified as it is recognised that the favoured touch microelectrode ('Beetrode') is fragile. It would be desirable that any touch microelectrode that might be developed would be autoclavable.

It would be desirable if more indwelling electrode (telemetry) centres were established. In addition, further developments of the present indwelling electrode technology available would be welcomed in order to improve miniaturisation and so, perhaps, make the technique useable in subjects other than the partially dentate.

Use of plaque $\mathrm{pH}$ methods in the assessment of cariogenic potential If a foodstuff is to be assessed for cariogenic and/or erosive potential, then two different methods (such as plaque $\mathrm{pH}$ and in situ modelling) should be used. It was considered important that plaque $\mathrm{pH}$ methods alone can only indicate a foodstuffs' acidogenic potential and possibly the cariogenic potential.

\section{Recommendations}

The San Antonio recommendations were that plaque $\mathrm{pH}$ methods were appropriate for the assessment of the acidogenicity/cariogenicity of foods and other oral products.

It was further agreed that:

- If the results of two independently performed plaque $\mathrm{pH}$ studies show the plaque $\mathrm{pH}$ profile of a foodstuff to be not statistically significantly different from that of a $10 \%$ sorbitol rinse (negative control or standard), then the food can effectively be considered as non-cariogenic.

- In the case when the results of two independently-performed plaque $\mathrm{pH}$ studies show that the plaque $\mathrm{pH}$ profile of a foodstuff falls below that of sorbitol but not to $\mathrm{pH} 5.7$, then an in situ cariogenicity test is required to further study the foodstuff.

- There may be a need for an 'intermediate' reference, in addition to the accepted positive control ( $10 \%$ sucrose) and negative control (10\% sorbitol) in order to compare foods of low cariogenic potential. The sorbitol reference should be made up with solid sorbitol diluted with distilled water to ensure a true $10 \%$ solution.

It was also noted that in taking the level of safety for teeth in $\mathrm{pH}$ depression as 'not below pH 5.7', then we are ignoring the potential of a foodstuff to cause demineralisation of any exposed roots (dentine/cementum), as the critical pH is higher for dentine than for enamel. Hence are 'safe for teeth' foodstuffs really just' safe for enamel? Further studies are therefore required to investigate the 'critical $\mathrm{pH}$ ' of dentine/cementum.

Use of plaque $\mathrm{pH}$ methods in the development of therapeutic agents Plaque $\mathrm{pH}$ remains a useful tool in the investigation of the development of oral therapeutic agents. ${ }^{11,15}$

\section{Conclusions}

It was concluded that all of the various plaque $\mathrm{pH}$ models were valid for research and assessment of the cariogenicity of foods, drinks, confectioneries and some oral health products. If a food passes the indwelling plaque $\mathrm{pH}$ method then it could be considered of no acidogenic or cariogenic potential. Food, confectionery or oral products may also be validly tested with the other plaque $\mathrm{pH}$ methods. If foods and oral products do not satisfy the rigorous requirements of the indwelling plaque $\mathrm{pH}$ method then the alternative methods may be used in combination and with the intra-oral cariogenicity test (ICT) that can be used to assess foods more reliably and with greater reproducibility than when used singly.

\section{Intra-oral cariogenicity (ICT) or in situ models}

Workshop group: D. Zero, V. Eastmond, S. Higham, K. J. Toumba, D. Scarrott

At the time of the San Antonio Conference in situ caries models had not been widely applied in the study of the cariogenicity of foods and this approach received only limited attention at that conference. Since then, there have been several conferences devoted to in situ models (two conferences in 1990, another in 1994 in the USA and another conference in Europe in 1994). In situ caries models involve the use of appliances or other devices that create defined conditions in the human mouth. These models simulate the process of dental caries. ${ }^{17,35}$ These models generally include all the multifactorial aspects of natural dental caries. That is a tooth substrate, either enamel or dentin; physiologically secreted saliva; the presence of dental plaque with cariogenic potential; a carbohydrate challenge (either experimentally controlled or provided by the subject's normal diet) and time, determined by the length of the experimental period. The main advantage of this approach is that foods and beverages can be tested under clinically relevant conditions and that very sensitive laboratory methods can be applied to measure changes in mineral status (demineralization/remineralization).

The role of the diet in the natural dental caries process is highly complex and is influenced by the many biological and behavioural factors involved in the caries aetiology. In situ studies permit the control of many of these variables. The main parameters that influence the response of in situ models have been the subject of several extensive review articles.$^{17-22}$

The most important experimental parameters that are under the control of the investigator and that influence the demineralization/remineralization response of in situ models are:

- The physical design of the model

- The characteristics of the subject panel

- The type of hard tissue substrate

- The method of assessing mineral status

- The study design

\section{Recommendations}

The UK workshop group reviewed each of these parameters in general terms and made the following recommendations. These are more extensive than those for the animal model and the plaque $\mathrm{pH}$ models as there has been substantial advances in this area since San Antonio.

\section{Physical design}

The designs of in situ models are quite varied, ranging from the classical partial denture model (intra-oral cariogenicity test) as 
described by Koulourides and co-workers, ${ }^{23}$ to fairly sophisticated models such as the intra-oral single-section model. ${ }^{24}$

In situ model systems can be broadly classified based on the physical design of the model, the type of hard tissue substrate and the method of assessing mineral status ${ }^{18}$ grouped in situ model systems into three categories:

- Removable appliances

- Single section model

- Banding models

Manning and Edgar grouped them as in vivo models and in situ models for de- and remineralization studies and also subdivided them into different methods based on the geographic location of the principal investigator. ${ }^{19}$ Each model system has unique characteristics that influence the response of the model. Several in situ models have been applied to the study of the cariogenicity of foods. ${ }^{18,25-29}$ The UK group agreed that the many model systems that have been developed could be applied to evaluate the cariogenicity of foods. The group also agreed that in situ models could be used in combination with plaque $\mathrm{pH}$ testing.

- Subject selection. Subjects selected for in situ studies should be without relevant health problems (such as infectious diseases, and salivary dysfunction). Extrapolation from adults to children is valid. Stookey recommended that adults rather than children are more appropriate as subjects for in situ studies. ${ }^{30}$ This was considering that caries rate, and response to preventive treatment, are similar for adults and children. Others have also noted this. ${ }^{31}$ Furthermore, adults generally have greater availability for appointments and are more likely to comply with clinical protocols.

- Inclusion/exclusion criteria should depend on the research objectives of a given study.

- Subject characteristics. Studies should detail subject characteristics by:

a) Age/gender

b) General health including medications

c) Saliva flow

d) Oral health status

e) Fluoride history; caries experience (past, active, etc. in order to show whether the model is high or low challenge)

- Standardisation of subjects. Where applicable this should be by using characteristics listed above.

- Consent. Subjects must give informed consent before participating in in situ studies.

\section{Hard tissue selection}

It is widely recognised that the type of hard tissue substrate will have a major impact on the response of an in situ model. In the case of pre-formed lesions, different methods of preparing a lesion will alter their demineralization/remineralization response. ${ }^{20,32}$ The UK Workshop group agreed on the following points:

- Studies should use human erupted teeth where possible.

- It is desirable to use a common tooth type and tooth surface within a study (but avoid being prescriptive, eg requiring premolars).

- Studies should specify the nature of the hard tissue substrate:

1. Status of tooth surface (intact, ground, polished, etc)

2. Dentine or enamel

3. Sound teeth or teeth with pre-formed lesions. When using specimens with pre-formed lesions their depth and mineral content should be uniform within a study.

- Infection control procedures should be adhered to in preparing and storing hard tissue specimens.
- Infection control and storage procedures should not have a detrimental effect on the structure and properties of the hard tissue substrate.

Substrate enamel selection was also discussed extensively by the workshop group on erosion (see later).

\section{Methods of measurement}

The key outcome measure for in situ studies is the net amount of demineralization or remineralization that has occurred over a defined study period. A number of reviews have been published on the wide array of methods that have been developed to quantify changes in mineral status of tooth specimens..$^{33,34,36}$

The UK group identified those methods that have received general acceptance by the research community. These included the following qualitative methods:

- Microhardness

- Polarised light

- Iodide permeability

- Optical methods

- Quantitative method

- Transverse microradiography (TMR)

Of the methods currently validated, TMR was considered to be the most informative, but is also the most demanding. Other methods are under development but have not yet been fully validated.

\section{Research design issues}

The San Antonio Conference did not make specific recommendations pertaining to in situ methodologies as they were, at that time, still in the development stage. The UK Workshop panel discussed several research design issues that impact on the outcome of in situ studies and recommended that studies should have the following minimum design features:

\section{General}

- Randomised crossover design.

- Lead-in procedures should be used to standardised oral conditions on entry of subjects into the study. This should involve a minimum of 2 weeks after a full oral cleaning by a dental hygienist, standardised use of toothpaste (see below) and refraining from using certain foods high in fluoride such as fish.

- Washout procedures to minimise risk of carryover effects should be for at least 2 weeks.

- Fluoride exposure should be standardised by providing a suitable toothpaste as well as standardised toothbrushes, and giving oral hygiene instructions.

- Compliance indicators should be included.

- A design with adequate statistical power should be used.

- Studies should be conducted based on good clinical practice standards.

- All studies should have been approved by a Human Subjects Internal Review Board (also known as an Institutional Human Subjects Review Board or Research Ethics Review Board)

Specific to the delivery of the food challenge

Studies should specify:

- Removable or fixed appliance (both acceptable).

- Frequency of exposure.

- Duration of exposure.

Frequency should reflect at least normal usage of the food product under study, and higher usage could be considered to show any effect of excessive consumption. Ideally, studies should be conducted with the test product in the mouth and in the presence of a normal diet. Extra oral challenges may also be appropriate for certain food products and in situ model systems. Model systems should 
be conducive to the formation of cariogenic plaque, ideally of a standard thickness. Controls should be appropriate to the study design and should include internal reference standards (ie 10\% sucrose and $10 \%$ sorbitol). The length of study should be determined by the sensitivity of a model to separate the positive $(10 \%$ sucrose) and negative control (10\% sorbitol).

\section{Conclusions}

The in situ methods have now been developed to an extent that they are valid methods to assess the cariogenicity of foods, drinks, confectioneries and some oral health products. Foods and other oral products can be assessed using the in situ model in combination with one or other of the plaque $\mathrm{pH}$ methods. Products passing the combination of in situ and plaque $\mathrm{pH}$ methods can be considered of no acidogenic or cariogenic potential.

\section{Erosion}

\section{Background}

The inclusion of erosion for the first time in these updated San Antonio guidelines reflects the increased importance of toothwear (mechanical and chemical) and dental erosion in the caseload of hospital and community based clinics. Erosion is believed to be the predominant cause of wear in children and young adults, although there will always be a contribution from attrition and abrasion. Indeed, erosion potentiates abrasive and attritive wear. The few prevalence studies to-date indicate that up to $8 \%$ of dentine is exposed in teenagers. ${ }^{37}$ This includes occlusal surfaces of the first molars as well as the palatal aspects of all the upper teeth. The recent Child Dental Health Survey in the United Kingdom reported that $2 \%$ of their teenage sample exhibited erosion into dentine or pulp in incisors. ${ }^{38}$ Whether this constitutes a dental public health problem in terms of treatment needs is not known. The development of methods to produce and measure erosion of enamel and dentine are necessary although, as yet, still in their infancy.

\section{Recommendations}

At the San Antonio Conference the question of erosion and its measurement and relationship to foods was not discussed. There have been, therefore, no previous recommendations. The UK Workshop group discussed the present state of knowledge on the subject of testing for erosive potential and made the following recommendations:

\section{Experimental production of lesion}

- Subject selection. Studies should detail subject characteristics by being based upon age and gender. An absence of risk factors associated with erosion must be determined, such as gastrooesophageal reflux disease (GORD), eating disorders etc.

- Enamel substrate. Various enamel substrates can be used in erosive potential appliances include cow (bovine), pig (porcine) and human (see also in situ models, above). Bovine enamel has problems because of concerns over bovine spongiform encephalitis, (BSE, prions) and increased porosity. Porcine has problems because of cultural and ethical acceptance. Human enamel, therefore, probably from premolars, is preferable. The source of the teeth used, with respect to water fluoridation, should be reported as should the age of the tooth donor at the time of extraction. The actual site from which enamel specimens are made should also be recorded.

- A non-polished surface is preferable. Although an abraded/ polished surface would give a more rapid response and would be a worst case scenario, the influence of acid erosion upon the aprismatic surface enamel, usually on smooth surfaces, would mimic the in vivo situation better. Some methods of measurement may not be appropriate for a curved non-polished surface and therefore the polished ground surface would have to be used.
- In situlin vivo versus in vitro acid erosion. The in vivo/in situ model for erosion studies is preferable. At present there is no agreement as to what constitutes the maximum erosion threshold at which a subject would have to be removed from the study. A pre-set 20 micron safety limit was set by Hughes et al. ${ }^{39}$

- Research design and clinical protocol. There should be a randomised crossover design with appropriate washout procedures/time to minimise risk of carry over effects. Control slabs should be cut from same tooth and site. The frequency of acid drink intake should be 3-6 times a day, and specified in any reports. Each aliquot of acid, or potentially erosive drink should be $15 \mathrm{mls}$ and should be HELD not drunk or swished for 60 seconds. The negative control drink should be a commercial mineral water, such as Volvic and the use should be standardised throughout each experiment.

- Internal reference standard. The internal reference standard should be a $10 \%$ citric acid solution. The duration of the study may be up to 2-3 weeks in length. Subjects should use a normal diet that should be continued throughout the study period but other drink intake should be restricted and monitored by way of diet sheets. The temperature of the experimental acid beverage as well as reference standards and negative control(s) should all be stated. The drinks may be chilled or at room temperature.

- Saliva. Artificial saliva should be included in any in vitro study.

- Site of enamel slab placement. The enamel slab(s) should be placed ideally as near to the natural teeth as possible and preferably not directly in the midline of the palate.

- Removable versus fixed appliance. At the time of the UK workshop there was no clear consensus as to whether a fixed appliance is preferable to a removable one. The group recognised that there were problems with compliance of the removable appliances, particularly in the light of the recommendation that the enamel slabs should be in place for 24 hours a day. The group also recognised the advantages of a removable over a fixed appliance, as it is possible to have greater control over experimental variables.

- Control for brushing. This was regarded as necessary to reduce as much as possible any variation in abrasive effects upon the eroded enamel surfaces.

- Control for the tongue. The group recognised the contribution from abrasive tongue contacts upon the experimental surfaces but it was felt that this would be extremely difficult to control for. In a crossover design the influence of the tongue would probably be the same for both experimental and control slabs.

Although it was recognised that in vitro experiments give limited information on the erosive potential of beverages or foods it was the opinion of the UK workshop group that such studies can nonetheless help to develop an in situ model technique.

\section{Measurement of the eroded surface}

Current techniques of characterising the surface of an eroded lesion include surface micro hardness $(\mathrm{SMH}),{ }^{40}$ profilometry, scanning electron microscopy (SEM ${ }^{41}$ micro radiography, ${ }^{42}$ digital image analysis, ${ }^{43}$ chemical analysis, iodide permeability and atomic force microscopy (AFM). Quantitative measurement for mineral loss is preferable to qualitative results gained from surface profilometry and scanning electron microscopy. The Group recommended transverse micro radiography (TMR) for both longitudinal studies and in situ model techniques. TMR will determine both lesion depth and volume per cent demineralisation. SMH and AFM can still be used. The latter has a potential in tapping mode. However, further development needs to be carried out with respect to the surface area that can be measured.

\section{Conclusions}

The study of mechanical and chemical toothwear and dental erosion in both children and adults across the developed and developing 
world lags far behind that of the study of caries. Future epidemiology and laboratory based studies will need to determine the extent of the problem, the strength of association of aetiological factors and what factors protect or reduce the erosivitity of drinks and food stuffs. Current methods of production of eroded lesions and their subsequent measurement are non-standardised and it is hoped that this consensus document will provide a framework for the standardisation of future models.

\section{Summary}

Assessment of the acidogenic and cariogenic erosive potential of foods requires the use of reproducible and standardised methods. The methodology laid down at the San Antonio conference in 1985 remain today the basis for research on and the testing of foods. The 1999 workshop has updated the appropriate methodology and introduced guidelines on the testing of erosive potential of foods. It is to be hoped that researchers wishing to evaluate foods and their effect on the teeth will continue to use these methods.

1 Hefferen J J. Proceedings of the Scientific Conference on methods for assessment of the cariogenic potential of foods. San Antonio, Texas Nov. 17-21, 1985. J Dent Res Sp issue 1986; 65: 1473-1544.

2 Navia J M. Experimental and husbandry procedures in rat caries research. In Tanzer J M (ed) Animal Models in Cariology. Microbiological Abstracts 1981. IRL, Washington DC.

3 Raubertus R F, Davis B A, Bowen W H, Pearson S K, Watson G E. Litter effects on caries in rats and implications for experimental design. Caries Res 1999; 33: 164-169.

4 Keyes P H. Dental caries in the molar teeth of rats. J Dent Res 1958; 37: 1088-1099.

5 Food and Drink Administration. Biological testing procedures for fluoride dentifrices. Docket No 80N-0042. Dockets management branch (HFA305), rm1-23, FDA, Rockville, MD, USA 1995

6 Mundorff-Shrestha S A, Shrestha B. The use of fluorescence for the detection of dental caries in rat molars. Caries Res 1997; 21: 683-687.

7 Miguel J C, Bowen, W H, Pearson S K. Effect of copper, iron and fluoride co-crystallised with sugar on caries development in desalivated rats. Archs Oral Biol 1997; 41: 1003-1010.

8 Lingstrom P, Imfield T, Birkhed D. Comparison of three different models for measurement of plaque $\mathrm{pH}$ in humans after consumption of soft bread and potato chips. J Dent Res 1993; 72: 865-870.

9 Scheie A A, Fejerskov O, Lingstrom P, Birkhed D, Manji F. Use of palladium touch micro- electrodes under field conditions for an in vivo assessment of dental plaque $\mathrm{pH}$ in children. Caries Res 1992; 26: 44-52.

10 Lingstrom P, lmfeld T, Birkhed D.Comparison of three different methods for measurement of plaque-pH in humans after consumption of soft bread and potato chips. J Dent Res 1993; 72: 865-870.

11 Preston A J. The determination of dental plaque $\mathrm{pH}$ in the evaluation of dentifrice components in human subjects. PhD Thesis, 1995, University of Liverpool, UK.

12 Curzon M E J, Pollard M. A Integration of methods for determining the acido-cariogenic potential of foods: a comparison of different methods. Caries Res 1996; 30: 126-131.

13 Tahmassebi J F, Duggal M S. Comparison of the plaque $\mathrm{pH}$ response acidogenic challenge in children and adults. Caries Res 1996; 30: 342-346.

14 Tahmassebi J, Duggal M S, Curzon M E J. Effect of a calcium carbonatebased toothpaste with $0.3 \%$ Triclosan on $\mathrm{pH}$ changes in dental plaque in vivo. Caries Res 1994; 28: 272-276.

15 Toumba K J, Duggal M S and May R J. In vivo plaque $\mathrm{pH}$ responses of a new soft drink in children (Abstract). J Dent Res 2000 Abst. 2165 79: 414.

16 Maquirre A, Rugg-Gunn A J, Wright G. Adaption of dental plaque to metabolise malitol compared with other sweetners. J Dent 2000; 28: 51-59. 17 Zero D T: In situ caries models. Adv Dent Res 1995; 9: 214-230.

18 Wefel J S. Effects of fluoride on caries development and progression using intra-oral models. J Dent Res 1990; 69 (Spec Iss): 626-633.

19 Manning R H, Edgar W M. Intra-oral models for studying de-and remineralization in man: methodology and measurement (a). J Dent Res 1992; 71(Spec Iss): 895-900.

20 ten Cate J M, van de Plassche-Simmons Y M, van Strijp A J P. Importance of model parameters in the assessment of intra-oral remineralization. $J$ Dent Res 1992; 71 (Spec Iss): 879-883.

21 ten Cate J M: In situ models, physico-chemical aspects. Adv Dent Res 1994; 8: $125-133$.

22 Fejerskov O, Nyvad B, Larsen M J. Human experimental caries models: intra-oral environmental variability. Adv Dent Res 1994; 8: 134-143.

23 Koulourides T, Phantumvanit P, Munksgaard E C, Housch T. An intra-ora model used for studies of fluoride incorporation in enamel. J Oral Pathol 1974; 3: 185-196.

24 Wefel J S, Jensen M E. An intra-oral single-section demineralization/ remineralization model. J Dent Res 1992; 71(Spec Iss): 860-863.

25 Silva M F de A, Jenkins G N, Burgess R C, Sandham H J. Effects of cheese on experimental caries in human subjects. Caries Res 1986; 20: 263-269.

26 Brudevold F, Goulet D, Attarzadeh F, Tehrani A. Demineralization potential of different concentrations of gelatinised wheat starch. Caries Res 1988; 22: 204-209,

27 Kashket S, Brudevold F, Yaskell T, Makonnen M. Increased permeability of enamel to iodide ions following ingestion of cookies varying in sucrose or fat content. Caries Res 1988; 22: 193-198.

28. Gedalia I, Ionat-Bendat D, Ben-Mosheh S, Shapira L. Tooth enamel softening with a cocoa type drink and rehardening with hard cheese or stimulated saliva. J Oral Rehab 1991; 18: 501-506,

29 Featherstone J D, Zero D T. An in situ model for simultaneous assessment of inhibition of demineralization and enhancement of remineralization. J Dent Res 1992; 71 (Spec Iss): 804-810.

30 Stookey G K. Reactor paper concerning patient selection and appliance design in intra-oral models. J Dent Res 1992; 71 (Spec Iss): 911-912.

31 Tahmassebi J Y, Duggal M S. Comparison of acidogenicity response in children and adults. Caries Res 1996; 30: 342-345.

32 Mellberg J R. Hard-tissue substrates for evaluation of cariogenic and anticariogenic activity in situ. J Dent Res 1992; 71 (Spec Iss): 913-919.

33 ten Bosch J J, Angmar-Månsson B. A review of quantitative methods for studies mineral content of intra-oral caries lesions. J Dent Res 1991; 70: 2-14.

34 Arends J, ten Bosch J J. Demineralization and remineralization evaluation techniques. J Dent Res (Spec Iss) 1992; 71: 924-928.

35 Brudevold F, Attarzadeh F, Tehrani A, van Houte J, Rouse J. Development of a new intra-oral demineralisation test. Caries Res 1984; 18: 421-429.

36 Jensen M E, Wefel J S. Effects of processed cheese on human plaque $\mathrm{pH}$ and demineralisation and demineralisation. Am J Dent 1990; 3: 217-223.

37 Milosevic A Young P J, Lennon M A. The prevalence of tooth wear in 4 year-old schoolchildren in Liverpool. Commun Dent Health 1994; 11: 83 -

38 O’Brien M. Children's Dental Health in the United Kingdom, 1993. Office of Population Censuses and Surveys. London: HMSO, 1994.

39 Hughes J A, West N X, Parker D M, Newcombe R G, Addy M. Development and evaluation of a low erosive blackcurrant juice in vitro and in situ. I. Comparison with orange juice. J Dent 1999; 27: 285-289.

40 Attin T, Koidl U, Buchalla W, Schaller H G, Kielbassa A M, Hellwig E. Correlation of microhardness and wear in differently eroded bovine dental enamel. Archs Oral Biol 1997; 42: 243-250.

41 Meurmen J H, Frank R. M. Scanning electron microscopic study of the effect of salivary pellicle on enamel erosion. Caries Res 1991; 25: 1-6.

42 Amechi B, Higham S M, Edgar W M. Use of transverse microradiography to quantify mineral loss by erosion in bovine enamel. Caries Res 1998; 32 351-356.

43 Mistry M, Grenby T H. Erosion by soft drinks of rat molar teeth assessed by digital image analysis. Caries Res 1993; 27: 21-25. 